\title{
Resenha
}

\section{INOVAR COM OS ATORES DO MUNDO RURAL: A PESQUISA-AÇÃO EM PARCERIA}

Maria Helena Rocha Antuniassi**

TRIOMPHE, B ${ }^{1}$; FAURE, G ${ }^{2}$; HOCDÉ, H. ${ }^{3}$; TEMPLE, L ${ }^{4}$; GASSELIN, $\mathrm{P}^{5}$. Inover avec les acteurs du monde rural: la recherche-action en partenariat. Coleção Agricultures en poches. Versailles: Ed. QUAE, 2015.

O livro tem por objetivo contribuir para sensibilizar e preparar os participantes para colocar em prática o desenvolvimento de uma modalidade de pesquisa-ação, a RAP (recherche-action en partenariat), definida como uma pesquisa que visa simultaneamente a produção de novos conhecimentos, a resolução de um problema identificado pelos participantes o reforço de suas capacidades para maior autonomia.

Com base em uma reflexão sistematizada, os autores buscam as chaves da reflexão para o aperfeiçoamento da pertinência e eficácia das praticas da citada pesquisa no domínio da agricultura em geral, da agroalimentar assim como do desenvolvimento rural e do maio ambiente, sobretudo nos países do Sul.

O trabalho se compõe de cinco partes desenvolvidas em vários tópicos. A primeira expõe a historia das diferentes abordagens da pesquisa ação, a segunda focaliza a questão da constituição da parceria dando ênfase nas estratégias para estabelecer a confiança e o dialogo entre os participantes e trazendo como exemplo uma experiência realizada no Brasil.

$\mathrm{Na}$ busca de seus objetivos, os autores iniciam a argumentação por uma reflexão sobre os fundamentos da pesquisa-ação, abordando uma série de temas pertinentes como: as origens desse tipo de pesquisa, ressaltando a obra pioneira de Lewis, as criticas e a evolução da pesquisa-ação lembrando as contribuições de Paulo Freire, a pesquisa ação no domínio do desenvolvimento e a pesquisa-ação na agricultura. Tais temas são desenvolvidos enfatizando a importância da analise sistêmica na execução da RAP tendo em vista sua capacidade de dar conta das interações entre os diversos elementos para explicar o funcio-

\footnotetext{
${ }^{1}$ Triomphe, B. - agrônomo - CIRAD - bernard.triomphe@cirad.fr

${ }^{2}$ Faure, G. - economista - CIRAD - Guy.Faure@cirad.fr

${ }^{3}$ Hocdé, H. - agrônomo - Cirad - henry.ocde@cirad.fr

${ }^{4}$ Temple, L. - economista - economista- CIRAD - ludovic.temple@cirad.fr

${ }^{5}$ Gasselin, P.- agrônomo e geografo - INRA - gasselin@suprago.inra.fr 
134

namento e as relações de causalidade implicadas no processo, mostrando como a RAP se inscreve numa abordagem sistêmica multi-referencial. Para isso, refere-se à abordagem AKIS (Agricultural knowledge and information systems), que consiste em analisar a informação e o conhecimento como um sistema que se pode modelizar, oferecendo recursos para a representação gráfica e os métodos qualitativos, de grande utilidade para explicitar e confrontar as percepções e visões dos participantes.

Em seguida é apresentada uma série de questões, cujas respostas justificam a utilização da "Pesquisa-ação em parceria" (RAP).

- Por que conduzir uma pesquisa ação em parceria?

- Por que os pesquisadores conduziriam uma RAP com os agricultores

- Por que os atores sociais conduziriam um projeto de transformação da sociedade rural em colaboração com os pesquisadores?

- Por que as empresas e as coletividades territoriais investiriam na pesquisa-ação em parceria?

Com base nas respostas, os autores concluem que a RAP se justifica fundamentando-se em dois grandes registros: o primeiro relativo ao domínio do sócio politica e se referindo ao papel da produção de conhecimento no processo de mudança das relações entre pesquisadores; técnicos e publico em geral; o segundo referindo-se ao domínio epistemológico, tendo em vista a concepção do conhecimento e da ciência, mostrando como a dimensão e a utilidade social do conhecimento são tão importantes no processo quanto sua produção.

No contexto das considerações dos autores, é importante ressaltar os princípios colocados como fundamentais no processo de desenvolvimento da pesquisa:
- $\quad$ inscrever a pesquisa na ação;

- produzir conhecimentos contextualizados considerando o meio ambiente e os problemas regionais, lembrando que para isso os participantes não pesquisadores, sobretudo os agricultores, devem ter a seu lado um quadro de técnicos conhecedores dos processos ambientais e socioeconômicos em curso no seu espaço de ação;

- "construir a pesquisa em conjunto, reconhecendo a importância da diferença de saberes, tendo em vista que todos os participantes não são somente atores, mas coautores" do processo da pesquisa, seus resultados e avaliação;

- estabelecer um processo interativo capaz de levar à formação de um quadro de valores compartilhados, tendo em vista a possibilidade do surgimento de conflitos oriundos da tensão entre empirismo e conceptualização e sobre o papel dos diferentes participantes não pesquisadores.

Tendo em vista seus objetivos e a maneira como os autores se empenharam para atingi-los, colocando toda a sua experiência à disposição dos leitores, consideramos que a obra se constitui em excelente material didático para quem se dispõe a trabalhar com o método da pesquisa-ação. 